\title{
Statins improve survival in patients previously treated with nivolumab for advanced non-small cell lung cancer: An observational study
}

\author{
MIWAKO OMORI $^{1,2}$, YUSUKE OKUMA ${ }^{1}$, TAIKI HAKOZAKI ${ }^{1}$ and YUKIO HOSOMI ${ }^{1}$ \\ ${ }^{1}$ Department of Thoracic Oncology and Respiratory Medicine, Tokyo Metropolitan Cancer and Infectious Diseases Center \\ Komagome Hospital, Tokyo 113-867; ${ }^{2}$ Department of Pulmonary Medicine and Oncology, \\ Graduate School of Medicine, Nippon Medical School, Tokyo 113-8603, Japan
}

Received May 8, 2018; Accepted November 6, 2018

DOI: $10.3892 / \mathrm{mco} .2018 .1765$

\begin{abstract}
There are a number of suggested predictive factors of nivolumab for non-small cell lung cancer (NSCLC), however, there is not enough evidence to determine a single factor that can predict the efficacy of nivolumab. As the progress of biomarkers for cancer treatment is improving, it has been speculated that certain clinical factors serve an important role when predicting the outcome of chemotherapy. A total of 67 patients treated with nivolumab for NSCLC from 2016-2017 were prospectively investigated. Age, sex, the Eastern Cooperative Oncology Group Performance Status, histology, epidermal growth factor receptor (EGFR) mutation, history of chemotherapy, smoking status, use of statins, use of fibrates, use of dipeptidyl peptidase-4 (DPP-4) inhibitors, and use of metformin were examined as clinical factors. Statistical analyses were performed using the Kaplan-Meier method and Cox regression adjusted for risk factors and the tumor response of 67 patients was assessed. The patients had a median age of 67 years (range, 36-87 years), and 46 males and 21 females were enrolled; performance status $0 / 1$ was 59 . Cases were categorized as adenocarcinoma $(n=41)$, squamous cell carcinoma $(n=17)$ and other $(n=9)$. A total of 13 patients (19.4\%) had EGFR mutations. These clinical factors
\end{abstract}

Correspondence to: Dr Yusuke Okuma, Department of Thoracic Oncology and Respiratory Medicine, Tokyo Metropolitan Cancer and Infectious Diseases Center Komagome Hospital, 3-18-22 Honkomagome, Bunkyo, Tokyo 113-867, Japan

E-mail: y-okuma@cick.jp

Abbreviations: ALK, anaplastic lymphoma kinase; CR, complete response; CTLs, cytotoxic $\mathrm{T}$ lymphocytes; DPP-4, dipeptidyl peptidase-4; EGFR, epidermal growth factor receptor; ICPi, immune checkpoint inhibitors; irAE, immune-related adverse events; NSCLC, non-small cell lung cancer; PD-1, programmed cell death-1; PD-L1, programmed cell death ligand-1; PR, partial response; RECIST, response evaluation citeria in solid tumors; TTF, treatment-to-failure

Key words: non-small cell lung cancer, statin, nivolumab, prognosis were not statistically significant in overall survival (OS). Clinical laboratory findings, complications and use of medical agents including antidiabetes mellitus or lipidemia were also analyzed. Statins exhibited statistical significance for response $(\mathrm{P}=0.02)$. Time-to-treatment failure (TTF) in statin-use group was not reached [95\% confidence interval (CI): 1.9-not reached] and was 4.0 months (95\% CI: 2.0-5.4) in the non-statin group $(\mathrm{P}=0.039)$. The median $\mathrm{OS}$ in statin-use group was not reached (95\% CI: 8.7-not reached) and was 16.5 months $(95 \%$ CI: 7.5-not reached) in the non-statin group ( $\mathrm{P}=0.058)$. NSCLC patients previously treated with nivolumab who were administered statins exhibited an increased response rate and longer TTF. This response was not statistically significant in OS.

\section{Introduction}

Lung cancer exhibits the greatest mortality rate of all types of cancer in men and women worldwide (1). Until recently, treatment for advanced lung cancer included only cytotoxic anticancer drugs. More recently, molecular target drugs that are much more tolerable and cause fewer adverse events have been developed (2). Notably, epidermal growth factor receptor (EGFR) tyrosine kinase inhibitors and anaplastic lymphoma kinase (ALK) inhibitors greatly improved the prognosis of specific patient subgroups with EGFR-activating mutations or ALK rearrangements (3). However, in later stages of advanced lung cancer, effective therapies are still limited.

Novel drugs including pembrolizumab, nivolumab, and atezolizumab, referred to as immune checkpoint inhibitors (ICPi), have been approved by the US Food and Drug Administration (FDA) for previously treated advanced non-small cell lung cancer (NSCLC). The Checkmate-017 (4), Checkmate-057 (5), KEYNOTE-010 (6) and OAK (7) trials demonstrated the superiority of these agents over docetaxel, which had previously been the standard of care for second-line therapy. ICPi block the interaction between programmed cell death-1 (PD-1) on activated cytotoxic T-lymphocytes (CTLs) and programmed cell death ligand-1 (PD-L1) on tumor cells, which inactivate the tumoricidal activity of CTLs (8). The response to ICPi is $20 \%$ (9). Certain factors, including PD-L1 expression, smoking history and EGFR mutations, 
were suggested to be predictive biomarkers in several clinical trials (10-13), but they are not enough to predict response with ICPi. In the meantime, the efficacy of PD-1 blockade therapy is considered to be relevant to metabolism (14-17). The association between metformin, a type 2 diabetes drug, and the efficacy of PD-1 blockade has been reported in vivo and in vitro (18). Other drugs that affect metabolism, such as statins, have also been reported to have antitumor effects (19). The off-target effects in combination with cytotoxic chemotherapy and metoformin/statin resulted in longer survival for elderly NSCLC patients due to attenuated chronic inflammation (20).

In the present study a prospective observational database was used to evaluate advanced NSCLC patients previously treated with nivolumab to investigate predictive biomarkers and the effects of drugs that affect metabolism.

\section{Patients and methods}

Patients and data acquisition. A total of 73 patients treated with nivolumab for advanced NSCLC in the first (recurrence after surgery), second or later lines of therapy at the Tokyo Metropolitan Cancer and Infectious Diseases Center Komagome Hospital (Tokyo, Japan) between January 2016 and February 2017 who did not participate in other clinical trials were identified using the database of the prospective observational study (UMIN registry no. UMIN000021694) and the study protocol was approved by the Ethics Committee of Tokyo Metropolitan Cancer and Infectious Diseases Center Komagome Hospital. Written informed consent from patients was waived for the present study by the Ethics Committee due to the observational nature of the protocol. The following clinical factors of lung cancer patients were examined: Age, sex, Eastern Cooperative Oncology Group Performance status (21), histology, EGFR mutation, history of chemotherapy, smoking status, use of statins, use of fibrates, use of dipeptidyl peptidase-4 (DPP-4) inhibitors and use of metformin. Patients treated with involumab in the present analysis was concurrently treated with statins, fibrateds, DDP-4 inhibitors, and metformin. The status of each patient at the beginning of nivolumab therapy was evaluated based on the use of statins by each patient. The same classification method was used for fibrates, DPP-4 inhibitors, and metformin.

Statistical analysis. Descriptive statistics was used to summarize the patients' baseline characteristics. The objective tumor response of nivolumab was determined following the Response Evaluation Criteria in Solid Tumors (RECIST) version 1.1 guidelines (22). The efficacy of nivolumab prior therapy was divided into two groups: Responders and non-responders. In patients treated with chemotherapy, responders were patients who achieved complete response (CR) or partial response (PR) according to the RECIST version 1.1 guidelines (23). Overall survival (OS) was defined as the time from the date of nivolumab treatment to the date of death for any reason. The time-to-treatment failure (TTF) was defined as the time from the date of initiation of nivolumab treatment to the date of disease progression or death. In any case of termination because of immune-related adverse events (irAE), the date of progression or death was defined as the event. Retreatment of nivolumab following recovery from irAE was permissive.

Univariate and multivariate analyses were conducted to identify the associations between the response to nivolumab therapy and the clinical characteristics of patients with advanced NSCLC. Categorical variables were tested for significance using Fisher's exact test or the $\chi^{2}$ test, as appropriate. Multivariate logistic regression analysis was used to assess the associations between patient variables and response to nivolumab therapy. TTF was estimated using Kaplan-Meier curves with a two-sided log-rank test. All P-values were two-sided, and $\mathrm{P}<0.05$ was considered to indicate a statistically significant difference. All statistical analyses were performed using the JMP 11 software (SAS Institute, Inc., Cary, NC, USA).

\section{Results}

Baseline characteristics. Among 73 patients treated with nivolumab as the second-line or later lines of chemotherapy, a total of 67 patients whose radiological response could be evaluated were included in this analysis. Patients had a median age of 67 years (36-87 years). A total of 46 male and 21 female patients were analyzed. A total of $41(61.2 \%)$ patients had adenocarcinoma, and 17 (25.4\%) patients had squamous cell carcinoma. A total of $13(19.4 \%)$ patients had EGFR mutation. At the time of initiation of nivolumab, 10 (14.9\%) patients were treated with statins. Other patient characteristics are detailed in Table I. The median follow-up time calculated from nivolumab treatment was 3.5 months. A total of 2 patients included with metformin at a dose of $250 \mathrm{mg} /$ day; 3 patients were included who were treated with $10 \mathrm{mg} /$ day atorvastatin; 1 patient was treated with $30 \mathrm{mg} /$ day of fluvastatin; 2 patients were treated with $2.5 \mathrm{mg} /$ day of rosuvastatin; 3 patients were treated with $5 \mathrm{mg}$ /day of pravastatin and 1 patient was treated with $2.5 \mathrm{mg} /$ day of pravastatin.

Clinical outcome. Of the 67 patients, 1 achieved a CR, 14 achieved a PR, 23 achieved stable disease status, and 25 developed progressive disease (PD) according to the RECIST criteria. A total of 4 patients were not evaluated for response due to early death or loss to follow-up. The objective response rate was $22.4 \%$ (Table II).

The results of univariate and multivariate analyses of variable factors of response in patients treated with nivolumab are presented in Table III. In the univariate analysis, patients treated with nivolumab as a first- or second-line therapy tended to have a better response rate than those receiving nivolumab as a later-line therapy [odds ratio (OR), 36.7 vs. $4.5 \%$, respectively; $\mathrm{P}=0.008]$. In addition, patients treated with statins at the time of initiation of nivolumab therapy tended to have a better response rate than those not treated with statins (ORR, 62.5 vs. $15.9 \%$, respectively; $\mathrm{P}=0.011$ ). Multivariate logistic regression demonstrated that the use of statins was independent of response to nivolumab therapy [OR, 0.011; 95\% confidence interval (CI): 1.35-40.10; $\mathrm{P}=0.021] . E G F R$ mutations were revealed to not be a predictive factor; none of the patients who had EGFR mutations was a responder.

TTF for all treated patients with nivolumab was 4.96 months (95\% CI: 2.66-7.62), and OS was not reached. 
Table I. Baseline characteristics of registered patients.

\begin{tabular}{|c|c|c|c|c|}
\hline Variants & Statins $(+)(n=10)$ & $\%$ & Statins $(-)(\mathrm{n}=57)$ & $\%$ \\
\hline Age, years [median (range)] & $70(53-78)$ & & $67(36-87)$ & \\
\hline \multicolumn{5}{|l|}{ Sex } \\
\hline Male & 8 & 80.0 & 38 & 66.7 \\
\hline Female & 2 & 20.0 & 19 & 33.3 \\
\hline \multicolumn{5}{|l|}{ PS } \\
\hline $0 / 1$ & 9 & 90.0 & 50 & 86.7 \\
\hline 2 & 1 & 10.0 & 7 & 13.3 \\
\hline \multicolumn{5}{|l|}{ Histological subtypes } \\
\hline Adenocarcinoma & 7 & 70.0 & 34 & 59.6 \\
\hline SQC & 2 & 20.0 & 15 & 26.3 \\
\hline NSCLC & 0 & 0 & 4 & 7.0 \\
\hline ADSQC & 0 & 0 & 2 & 3.6 \\
\hline LCNEC & 1 & 10.0 & 1 & 1.8 \\
\hline Large cell carcinoma & 0 & 0 & 1 & 1.8 \\
\hline \multicolumn{5}{|l|}{ EGFR mutation } \\
\hline Wild-type & 10 & 100.0 & 34 & 77.2 \\
\hline EGFR exon 19 del & 0 & 0 & 7 & 12.2 \\
\hline EGFR exon21 L858R & 0 & 0 & 6 & 10.6 \\
\hline Lines of chemotherapy, median (range) & $2(2-4)$ & & $2(1-5)$ & \\
\hline \multicolumn{5}{|l|}{ Smoking Status } \\
\hline Current or former & 8 & 100 & 47 & 82.5 \\
\hline Never & 0 & 0 & 10 & 17.5 \\
\hline \multicolumn{5}{|l|}{ Use of fibrates } \\
\hline Yes & 0 & 0 & 4 & 7.0 \\
\hline No & 10 & 100 & 53 & 93.0 \\
\hline \multicolumn{5}{|l|}{ Use of DPP-4 inhibitors } \\
\hline Yes & 3 & 30.0 & 2 & 3.5 \\
\hline No & 7 & 70.0 & 55 & 96.5 \\
\hline \multicolumn{5}{|l|}{ Use of metformin } \\
\hline Yes & 1 & 10.0 & 1 & 1.8 \\
\hline No & 9 & 90.0 & 56 & 98.2 \\
\hline
\end{tabular}

PS, performance status; SQC, squamous cell carcinoma; NSCLC, non-small cell lung cancer; ADSQC, adenosquamous cell carcinoma; LCNEC, large cell neuroendocrine carcinoma; EGFR, epidermal growth factor receptor; DPP-4, dipeptidyl-peptidase-4.

Table II. Objective response to treatment.

\begin{tabular}{lcr}
\hline Objective response & Patients, $\mathrm{n}$ & $(\%)$ \\
\hline CR & 1 & 1.5 \\
PR & 14 & 20.9 \\
SD & 23 & 34.3 \\
PD & 25 & 37.3 \\
NE & 4 & 6.0 \\
Overall response rate (\%) & 15 & 22.4 \\
\hline
\end{tabular}

CR, complete response; PR, partial response; $\mathrm{SD}$, stable disease; PD, progressive disease; $\mathrm{NE}$, not evaluate.

TTF of statin (+) group was not reached (95\% CI: $1.9-$-not reached), whereas TTF of statin (-) group was 4.0 months (95\% CI: 2.0-5.4; $\mathrm{P}=0.039$; Fig. $1 \mathrm{~A}$ and $\mathrm{B}$ ). OS of statin (+) group was not reached (95\% CI: 8.7-not reached) and OS of statin (-) was 16.5 months (95\% CI: 7.5-not reached; $\mathrm{P}=0.058$; Fig. 2A and B).

\section{Discussion}

The results of the present study demonstrated that the use of statins led to a good response in patients treated with nivolumab for advanced NSCLC. A number of predictive biomarkers of nivolumab or other immune checkpoint blockade therapies have been previously proposed. PD-L1 expression on tumor cells was demonstrated to be a possible biomarker predictor of nivolumab or other immune checkpoint blockade therapies in patients with advanced NSCLC, melanoma or renal cell cancer $(5,6,22)$. Besides PD-L1 expression of the tumor tissue, smoking history and oncogenic driver mutations (EGFR mutation and ALK fusion) were previously suggested to be predictive biomarkers $(5,6)$. In addition, previous studies revealed that counts of neutrophils, lymphocytes, eosinophils 
Table III. Univariate and multivariate analyses of variable factors of response in previously treated NSCLC patients treated with nivolumab.

\begin{tabular}{|c|c|c|c|c|c|c|c|}
\hline \multirow[b]{2}{*}{ Characteristic } & \multirow[b]{2}{*}{$\mathrm{RR}(\%)$} & \multicolumn{3}{|c|}{ Univariate analysis } & \multicolumn{3}{|c|}{ Multivariate analysis } \\
\hline & & OR & $95 \% \mathrm{CI}$ & P-value & OR & $95 \% \mathrm{CI}$ & P-value \\
\hline \multicolumn{8}{|l|}{ Age, years } \\
\hline$<70$ & 26.5 & 0.56 & $0.08-2.74$ & 0.51 & & & \\
\hline$\geq 70$ & 16.7 & & & & & & \\
\hline \multicolumn{8}{|l|}{$\operatorname{Sex}$} \\
\hline Male & 24.3 & 1.27 & $0.26-8.63$ & 1.00 & & & \\
\hline Female & 20.0 & & & & & & \\
\hline \multicolumn{8}{|l|}{ PS } \\
\hline$<2$ & 23.4 & 0.82 & $0.02-9.53$ & 1.00 & & & \\
\hline$\geq 2$ & 20.0 & & & & & & \\
\hline \multicolumn{8}{|l|}{ Histology } \\
\hline SQC & 30.8 & 1.70 & $0.30-8.39$ & 0.47 & 1.27 & $0.27-6.11$ & 0.76 \\
\hline Other & 20.5 & & & & & & \\
\hline \multicolumn{8}{|l|}{ EGFR mutations } \\
\hline Yes & 0 & 0 & $0-1.35$ & 0.09 & 0.00 & $0.00-\mathrm{NR}$ & 0.99 \\
\hline No & 28.6 & & & & & & \\
\hline \multicolumn{8}{|c|}{ Lines of chemotherapy } \\
\hline 2 or 3 & 36.7 & 11.67 & $1.45-546.00$ & 0.01 & & & \\
\hline$\geq 4$ & 4.5 & & & & & & \\
\hline \multicolumn{8}{|l|}{ Smoking status } \\
\hline Current/former & 23.9 & 1.56 & $0.15-80.96$ & 1.00 & 0.24 & $0.01-4.49$ & 0.34 \\
\hline Never & 16.7 & & & & & & \\
\hline \multicolumn{8}{|l|}{ Use of statin } \\
\hline Yes & 62.5 & 8.29 & $1.29-66.58$ & 0.01 & 7.37 & $1.35-40.10$ & 0.02 \\
\hline No & 15.9 & & & & & & \\
\hline \multicolumn{8}{|l|}{ Use of fibrate } \\
\hline Yes & 50.0 & 3.42 & $0.04-284.54$ & 0.41 & & & \\
\hline No & 22.0 & & & & & & \\
\hline \multicolumn{8}{|c|}{ Use of DPP-4 inhibitor } \\
\hline Yes & 25.0 & 1.12 & $0.020-15.64$ & 1.00 & & & \\
\hline No & 22.9 & & & & & & \\
\hline \multicolumn{8}{|l|}{ Use of metformin } \\
\hline Yes & 100 & Inf & 0.09-Inf & 0.23 & & & \\
\hline No & 21.6 & & & & & & \\
\hline
\end{tabular}

RR, response rate; OR, odds ratio; PS, performance status; SQC, squamous cell carcinoma; NR, not reached; CI, confidence interval; EGFR, epidermal growth factor receptor; DPP-4, dipeptidyl peptidase4; Inf, infinity.

and lactate dehydrogenase levels in the peripheral blood could be predictive biomarkers of ipilimumab therapy for melanoma (24-26). However, evidence is not sufficient to use these indicators as predictive biomarkers. Therefore, in the present study, various markers were analyzed in patients treated with nivolumab for advanced NSCLC to assess predictability.

In the present study of nivolumab therapy, the response of patients treated with statins was better than that of patients not treated with statins. Cellular metabolism is considered to be important to immunotherapy of cancer (27). In fact, DPP-4 and metformin inhibitors have been reported to enhance anticancer effects of ICPi in vivo or in vitro $(16,18,28)$. In the present study, patients treated with DPP-4 inhibitors or metformin were few and did not exhibit a significantly good response. Chamoto et al (29) recently reported that bezafibrate enhanced tumor-growth suppression and animal-survival activities by anti-PD-L1 monoclonal antibody. Statins, inhibitors of 3-hydroxy-3-methylglutaryl coenzyme A reductase, are efficient and widely used drugs in the treatment of cardiovascular diseases and lipid disorders, especially hypercholesterolemia (28-30). Conversely, statins have been previously reported to prolong the survival and decrease the incidence of patients with various cancers (30-32). The mechanism of the anticancer activity of statins remains unclear, but a previous review has demonstrated this anticancer effect (33). Mitogen-activated protein kinase and extracellular signal-regulated kinase upregulate antiapoptotic molecules in small cell lung cancer (SCLC) cells $(34,35)$, and simvastatin 
A

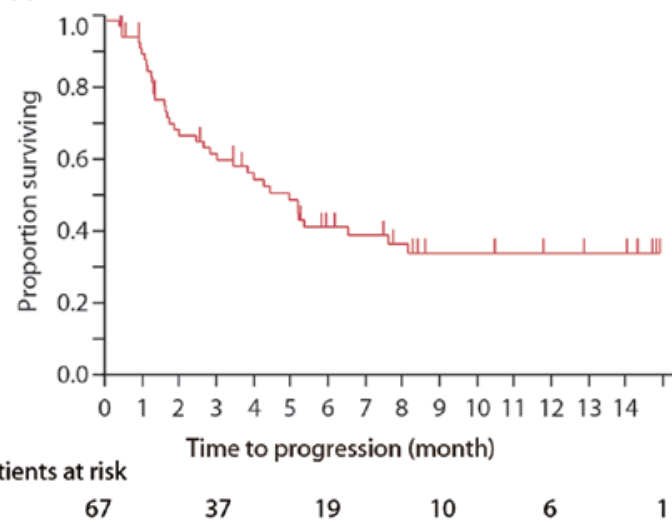

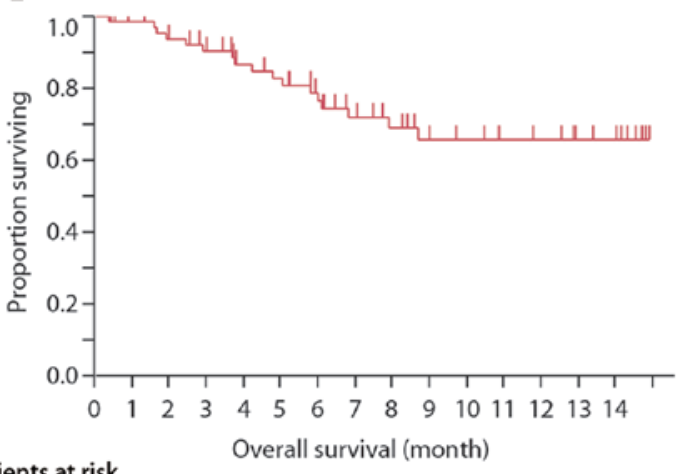

Patients at risk
Overall survival (month)

$\begin{array}{llllll}67 & 53 & 37 & 20 & 16 & 1\end{array}$

Figure 1. (A) The estimated Kaplan-Meier curves for treatment-to-failure in all patients treated with nivolumab. (B) The estimated Kaplan-Meier curves for overall survival in all patients treated with nivolumab.
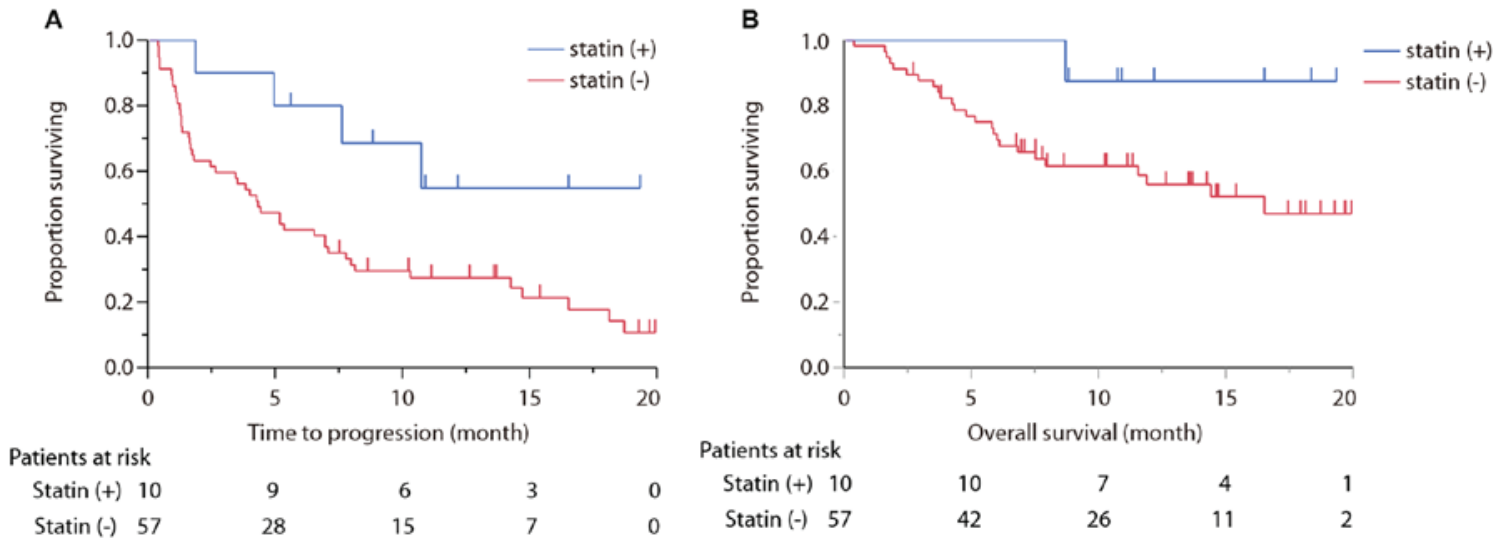

Figure 2. (A) Survival curve comparing statin (+) group and statin (-) group in treatment-to-failure demonstrating statistically significance (P=0.025). (B) Survival curve comparing statins (+) group and statins (-) group in overall survival exhibited a significant improvement in the statin (+) group (P=0.058).

can disrupt this process through impaired Ras superfamily signaling (34-36). Statins also have a potentially synergic effect in combination with cytotoxic chemotherapy (36-38). In the clinical setting, metformin and statin attenuates chronic inflammation (and stabilization TP53 function), which demonstrated the survival benefit in combination with EGFR tyrosine kinase inhibitor for EGFR mutation-positive NSCLC (39) and reduced cancer risk in Korean nation-wide surveillance (40). In the present study, nivolumab demonstrated similar tendency for survival. A number of previous in vitro studies have demonstrated that statins arrest cells in the G1 or S phase by affecting cell-cycle regulatory proteins such as cyclins, cyclin-dependent kinases (CDKs), and inhibitors of CDK $(33,41,42)$. In addition, statins have been considered to lead to apoptosis of cancer cells through effects of various molecules such as B cell lymphoma (Bcl)-2, Bcl-2-associated $\mathrm{X}$ protein and caspase $3(33,43-45)$. Furthermore, statins have been demonstrated to inhibit intracellular signaling pathways in cancer cells (33). Other studies have reported that statins activated anticancer immunity and may reduce the development of cancer cells and metastasis $(46,47)$. One previous study reported that human melanoma cells with statins increased major histocompatibility complex (MHC) class I chain-related protein A (MICA) membrane expression and made melanoma cells more sensitive to NK cells (46).
Conversely, previous reports have also linked the use of statins to immunity suppression (48). Cholesterol has been reported to induce a conformational change of the transmembrane domain of MHC II (49), so it is presumed that statins modify conformation and the function of immune-related molecules, such as MHCs, and affect anticancer immunity. This theory suggests that statins may increase anticancer effects of the ICPi through activation of $\mathrm{T}$ cells. Overall, the present study reveals a potential improved efficacy of ICPi; however, there is no biological plausibility to illustrate.

The present study had limitations. First, only a small number of patients were treated $(n=10)$ with statins. It was also difficult to evaluate the effects of confounding. Secondly, another limitation was that dose and duration of statins and level of cholesterol in the peripheral blood were unknown. Third, PD-L1 expression of tumor cells in patients prior to treatment was unknown, since IHC of PD-L1 expression is not a requirement when using nivolumab. Therefore, correlation of PD-L1 expression was not evaluated.

A definite single predictive biomarker of ICPi has not yet been identified and it has been suggested that the interaction of several clinical or biological elements of the 'cancer immunogram' are associated with response to ICPis (50). The relevance of the mevalonate pathway and ICPi is estimated in various mechanisms in the cancer biology, 
but clinical studies with statins for SCLC patients were not previously demonstrated to benefit the survival (51); however, nivolumab in NSCLC was not performed. The results of the present study suggest that combination therapy of nivolumab and statins improve the survival rate and should be further investigated.

In the present study, it was demonstrated that the use of statins was associated with better response and longer TTF in patients with advanced NSCLC treated with nivolumab. Further investigations on the predictive and clinical relevance of ICPi are required.

\section{Acknowledgements}

The authors thank Dr Makoto Saito, the Senior Biostatistician in the Office for Clinical Research Support in Tokyo Metropolitan Cancer and Infectious diseases Center Komagome Hospital (Tokyo, Japan) for statistical advice.

\section{Funding}

No funding was received.

\section{Availability of data and materials}

All data generated or analyzed during this study are included in this published article.

\section{Authors' contributions}

MO, YO, and TH analyzed the NSCLC patient treated with nivolumab, and were major contributors in writing this manuscript. YO and YH analyzed and interpreted the patient data. All authors read and approved the final manuscript.

\section{Ethics approval and consent to participate}

All study protocols were approved by the Institutional Review Committee of Tokyo Metropolitan Cancer and Infectious diseases Center Komagome Hospital (Tokyo, Japan).

\section{Patient consent for publication}

Not applicable.

\section{Competing interests}

Yukio Hosomi has received honoraria from AstraZeneca (Osaka, Japan); Taiho Pharmaceutical Co., Ltd. (Tokyo, Japan); Chugai Pharmaceutical Co, Ltd. (Tokyo, Japan); Ono Pharmaceutical Co., Ltd. (Tokyo, Japan); Bristol-Myers Squibb (New York, NY, USA) and Boehringer Ingelheim (Ingelheim, Germany).

\section{References}

1. Siegel RL, Miller KD and Jemal A: Cancer statistics, 2016. CA Cancer J Clin 66: 7-30, 2016.

2. Ramalingam S and Belani C: Systemic chemotherapy for advanced non-small cell lung cancer: Recent advances and future directions. Oncologist 13 (Suppl 1): 5-13, 2008.
3. Reck M, Popat S, Reinmuth N, De Ruysscher D, Kerr KM and Peters S; ESMO Guidelines Working Group: Metastatic non-small cell lung cancer (NSCLC): ESMO Clinical Practice Guidelines for diagnosis, treatment and follow-up. Ann Oncol 25 (Suppl 3): iii27-iii39, 2014.

4. Brahmer J, Reckamp KL, Baas P, Crinò L, Eberhardt WE, Poddubskaya E, Antonia S, Pluzanski A, Vokes EE, Holgado E, et al: Nivolumab versus docetaxel in advanced squamous-cell non-small cell lung cancer. N Engl J Med 373: 123-135, 2015.

5. Borghaei H, Paz-Ares L, Horn L, Spigel DR, Steins M, Ready NE, Chow LQ, Vokes EE, Felip E, Holgado E, et al: Nivolumab versus docetaxel in advanced nonsquamous non-small-cell lung cancer. N Engl J Med 373: 1627-1639, 2015.

6. Herbst RS, Baas P, Kim DW, Felip E, Pérez-Gracia JL, Han JY, Molina J, Kim JH, Arvis CD, Ahn MJ, et al: Pembrolizumab versus docetaxel for previously treated, PD-L1-positive, advanced non-small-cell lung cancer (KEYNOTE-010): A randomised controlled trial. Lancet 387: 1540-1550, 2016

7. Rittmeyer A, Barlesi F, Waterkamp D, Park K, Ciardiello F, von Pawel J, Gadgeel SM, Hida T, Kowalski DM, Dols MC, et al; OAK Study Group: Atezolizumab versus docetaxel in patients with previously treated non-small-cell lung cancer (OAK): A phase 3, open-label, multicentre randomised controlled trial. Lancet 389: 255-265, 2017.

8. Sznol M and Chen L: Antagonist antibodies to PD-1 and B7-H1 (PD-L1) in the treatment of advanced human cancer. Clin Cancer Res 19: 1021-1034, 2013.

9. Soria JC, Marabelle A, Brahmer JR and Gettinger S: Immune checkpoint modulation for non-small cell lung cancer. Clin Cancer Res 21: 2256-2262, 2015.

10. Ramalingam S, Hui R, Gandhi L, Carcereny E, Felip E, Ahn MJ, Eder JP, Balmanoukian AS, Leighl N, Aggarwal C, et al: P2.39: Long-term OS for patients with advanced NSCLC enrolled in the KEYNOTE-001 study of pembrolizumab: Track: Immunotherapy. J Thorac Oncol 11 (10S): S241-S242, 2016.

11. Matter-Walstra K, Schwenkglenks M, Aebi S, Dedes K, Diebold J, Pietrini M, Klingbiel D, von Moos R and Gautschi O; Swiss Group for Clinical Cancer Research: A cost-effectiveness analysis of nivolumab versus docetaxel for advanced nonsquamous NSCLC including PD-L1 testing. J Thorac Oncol 11: 1846-1855, 2016.

12. Langer CJ, Gadgeel SM, Borghaei H, Papadimitrakopoulou VA, Patnaik A, Powell SF, Gentzler RD, Martins RG, Stevenson JP Jalal SI, et al; KEYNOTE-021 investigators: Carboplatin and pemetrexed with or without pembrolizumab for advanced, non-squamous non-small-cell lung cancer: A randomised, phase 2 cohort of the open-label KEYNOTE-021 study. Lancet Oncol 17: 1497-1508, 2016.

13. Fehrenbacher L, Spira A, Ballinger M, Kowanetz M, Vansteenkiste J, Mazieres J, Park K, Smith D, Artal-Cortes A, Lewanski C, et al; POPLAR Study Group: Atezolizumab versus docetaxel for patients with previously treated non-small-cell lung cancer (POPLAR): A multicentre, open-label, phase 2 randomised controlled trial. Lancet 387: 1837-1846, 2016.

14. Pearce EL, Walsh MC, Cejas PJ, Harms GM, Shen H, Wang LS, Jones RG and Choi Y: Enhancing CD8 T-cell memory by modulating fatty acid metabolism. Nature 460: 103-107, 2009.

15. Rolf J, Zarrouk M, Finlay DK, Foretz M, Viollet B and Cantrell DA: AMPK 1 1: A glucose sensor that controls CD8 T-cell memory. Eur J Immunol 43: 889-896, 2013.

16. Araki K and Ahmed R: AMPK: A metabolic switch for CD8+ T-cell memory. Eur J Immunol 43: 878-881, 2013.

17. Eikawa S, Nishida M, Mizukami S, Yamazaki C, Nakayama E and Udono H: Immune-mediated antitumor effect by type 2 diabetes drug, metformin. Proc Natl Acad Sci USA 112: 1809-1814, 2015.

18. Scharping NE, Menk AV, Whetstone RD, Zeng $X$ and Delgoffe GM: Efficacy of PD-1 blockade is potentiated by metformin-induced reduction of tumor hypoxia. Cancer Immunol Res 5: 9-16, 2017.

19. Gruenbacher G and Thurnher M: Mevalonate metabolism in cancer. Cancer Lett 356: 192-196, 2015.

20. Lee YG, Lee JH, Jang JS and Kim JH: Prognostic benefit of taking statin and/or metformin in elderly patients with advanced non-small cell lung cancer: A nationwide population-based epidemiologic study. J Clin Oncol 36: 10045-10045, 2018.

21. Cancer Therapy Evaluation Program. Common Toxicity Criteria, Version 2.0. DCTD, NCI, NIH, DHHS March 1998. https://ctep. cancer.gov/protocoldevelopment/electronic_applications/docs/ ctcv20_4-30-992.pdf. 
22. Eisenhauer EA, Therasse P, Bogaerts J, Schwartz LH, Sargent D, Ford R, Dancey J, Arbuck S, Gwyther S, Mooney M, et al: New response evaluation criteria in solid tumours: Revised RECIST guideline (version 1.1). Eur J Cancer 45: 228-247, 2009.

23. Schwartz LH, Litière S, de Vries E, Ford R, Gwyther S, Mandrekar S, Shankar L, Bogaerts J, Chen A, Dancey J, et al: RECIST 1.1-Update and clarification: From the RECIST committee. Eur J Cancer 62: 132-137, 2016.

24. Ku GY, Yuan J, Page DB, Schroeder SE, Panageas KS, Carvajal RD, Chapman PB, Schwartz GK, Allison JP and Wolchok JD: Single-institution experience with ipilimumab in advanced melanoma patients in the compassionate use setting: Lymphocyte count after 2 doses correlates with survival. Cancer 116: 1767-1775, 2010

25. Delyon J, Mateus C, Lefeuvre D, Lanoy E, Zitvogel L, Chaput N, Roy S, Eggermont AM, Routier E and Robert C: Experience in daily practice with ipilimumab for the treatment of patients with metastatic melanoma: An early increase in lymphocyte and eosinophil counts is associated with improved survival. Ann Oncol 24: 1697-1703, 2013.

26. Ferrucci PF, Ascierto PA, Pigozzo J, Del Vecchio M, Maio M, Antonini Cappellini GC, Guidoboni M, Queirolo P, Savoia $\mathrm{P}$, Mandalà $\mathrm{M}$, et al: Baseline neutrophils and derived neutrophil-to-lymphocyte ratio: Prognostic relevance in metastatic melanoma patients receiving ipilimumab. Ann Oncol 27: 732-738, 2016

27. Gubin MM, Zhang X, Schuster H, Caron E, Ward JP, Noguchi T, Ivanova Y, Hundal J, Arthur CD, Krebber WJ, et al: Checkpoint blockade cancer immunotherapy targets tumour-specific mutant antigens. Nature 515: 577-581, 2014

28. Barreira da Silva R, Laird ME, Yatim N, Fiette L, Ingersoll MA and Albert ML: Dipeptidylpeptidase 4 inhibition enhances lymphocyte trafficking, improving both naturally occurring tumor immunity and immunotherapy. Nat Immunol 16: 850-858, 2015.

29. Chamoto K, Chowdhury PS, Kumar A, Sonomura K, Matsuda F, Fagarasan S and Honjo T: Mitochondrial activation chemicals synergize with surface receptor PD-1 blockade for T cell-dependent antitumor activity. Proc Natl Acad Sci USA 114: E761-E770, 2017.

30. Nielsen SF, Nordestgaard BG and Bojesen SE: Statin use and reduced cancer-related mortality. N Engl J Med 367: 1792-1802, 2012.

31. Cardwell CR, Hicks BM, Hughes C and Murray LJ: Statin use after colorectal cancer diagnosis and survival: A population-based cohort study. J Clin Oncol 32: 3177-3183, 2014

32. Yu O, Eberg M, Benayoun S, Aprikian A, Batist G, Suissa S and Azoulay L: Use of statins and the risk of death in patients with prostate cancer. J Clin Oncol 32: 5-11, 2014.

33. Bernhart E, Damm S, Wintersperger A, Nusshold C, Brunner AM, Plastira I, Rechberger G, Reicher H, Wadsack C, Zimmer A, et al: Interference with distinct steps of sphingolipid synthesis and signaling attenuates proliferation of U87MG glioma cells. Biochem Pharmacol 96: 119-130, 2015.

34. Pardo OE, Lesay A, Arcaro A, Lopes R, Ng BL, Warne PH, McNeish IA, Tetley TD, Lemoine NR, Mehmet H, et al: Fibroblast growth factor 2-mediated translational control of IAPs blocks mitochondrial release of Smac/DIABLO and apoptosis in small cell lung cancer cells. Mol Cell Biol 23: 7600-7610, 2003.

35. Pardo OE, Wellbrock C, Khanzada UK, Aubert M, Arozarena I, Davidson S, Bowen F, Parker PJ, Filonenko VV, Gout IT, et al: FGF-2 protects small cell lung cancer cells from apoptosis through a complex involving PKCepsilon, B-Raf and S6K2 EMBO J 25: 3078-3088, 2006.

36. Kozar K, Kaminski R, Legat M, Kopec M, Nowis D, Skierski JS, Koronkiewicz M, Jakóbisiak M and Golab J: Cerivastatin demonstrates enhanced antitumor activity against human breast cancer cell lines when used in combination with doxorubicin or cisplatin. Int J Oncol 24: 1149-1157, 2004.
37. Holstein SA and Hohl RJ: Synergistic interaction of lovastatin and paclitaxel in human cancer cells. Mol Cancer Ther 1: 141-149, 2001.

38. Feleszko W and Jakóbisiak M: Lovastatin augments apoptosis induced by chemotherapeutic agents in colon cancer cells. Clin Cancer Res 6: 1198-1199, 2000.

39. Rodriguez OGA, Barron FB, Padilla MÁS, Ramirez-Tirado LA, Flores-Estrada D, Cruz-Rico G, Jiménez MJA and Zorrilla AFC: Combination of metformin plus TKI vs. TKI alone in EGFR(+) LUNG adenocarcinoma: A randomized phase II study. J Clin Oncol 36: 9013-9013, 2018.

40. Kim HJ, Lee S, Chun KH, Jeon JY, Han SJ, Kim DJ, Kim YS, Woo JT, Nam MS, Baik SH, et al: Metformin reduces the risk of cancer in patients with type 2 diabetes: An analysis based on the Korean National Diabetes Program Cohort. Medicine (Baltimore) 97: e0036, 2018.

41. Rao S, Porter DC, Chen X, Herliczek T, Lowe M and Keyomarsi K: Lovastatin-mediated G1 arrest is through inhibition of the proteasome, independent of hydroxymethyl glutaryl-CoA reductase. Proc Natl Acad Sci USA 96: 7797-7802, 1999.

42. Tu YS, Kang XL, Zhou JG, Lv XF, Tang YB and Guan YY: Involvement of Chk1-Cdc25A-cyclin A/CDK2 pathway in simvastatin induced S-phase cell cycle arrest and apoptosis in multiple myeloma cells. Eur J Pharmacol 670: 356-364, 2011

43. Cafforio P, Dammacco F, Gernone A and Silvestris F: Statins activate the mitochondrial pathway of apoptosis in human lymphoblasts and myeloma cells. Carcinogenesis 26: 883-891, 2005.

44. Qi XF, Zheng L, Lee KJ, Kim DH, Kim CS, Cai DQ, Wu Z, Qin JW, Yu YH and Kim SK: HMG-CoA reductase inhibitors induce apoptosis of lymphoma cells by promoting ROS generation and regulating Akt, Erk and p38 signals via suppression of mevalonate pathway. Cell Death Dis 4: e518, 2013.

45. Spampanato C, De Maria S, Sarnataro M, Giordano E, Zanfardino M, Baiano S, Cartenì M and Morelli F: Simvastatin inhibits cancer cell growth by inducing apoptosis correlated to activation of Bax and down-regulation of BCL-2 gene expression. Int J Oncol 40: 935-941, 2012.

46. Moghim S, Sarikhani E, Nasr Esfahani B and Faghri J: Identification of nontuberculous mycobacteria species isolated from water samples using phenotypic and molecular methods and determination of their antibiotic resistance patterns by E-test method, in Isfahan, Iran. Iran J Basic Med Sci 15: 1076-1082, 2012.

47. Bennaceur K, Atwill M, Al Zhrany N, Hoffmann J, Keavney B, Breault D, Richardson G, von Zglinicki T, Saretzki G and Spyridopoulos I: Atorvastatin induces $\mathrm{T}$ cell proliferation by a telomerase reverse transcriptase (TERT) mediated mechanism. Atherosclerosis 236: 312-320, 2014.

48. Ulivieri C, Fanigliulo D, Benati D, Pasini FL and Baldari CT: Simvastatin impairs humoral and cell-mediated immunity in mice by inhibiting lymphocyte homing, T-cell activation and antigen cross-presentation. Eur J Immunol 38: 2832-2844, 2008.

49. Roy K, Ghosh M, Pal TK, Chakrabarti S and Roy S: Cholesterol lowering drug may influence cellular immune response by altering MHC II function. J Lipid Res 54: 3106-3115, 2013.

50. Blank CU, Haanen JB, Ribas A and Schumacher TN: CANCER IMMUNOLOGY. The 'cancer immunogram'. Science 352: 658-660, 2016

51. Seckl MJ, Ottensmeier CH, Cullen M, Schmid P, Ngai Y, Muthukumar D, Thompson J, Harden S, Middleton G, Fife KM, et al: Multicenter, phase III, randomized, double-blind, placebo-controlled trial of pravastatin added to first-line standard chemotherapy in small-cell lung cancer (LUNGSTAR). J Clin Oncol 35: 1506-1514, 2017. 